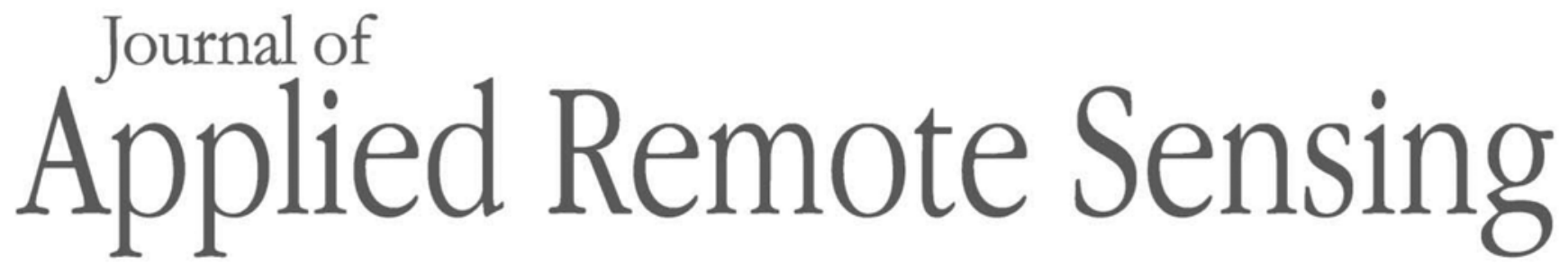

RemoteSensing.SPIEDigitalLibrary.org

\title{
How much benthic information can be retrieved with hyperspectral sensor from the optically complex coastal waters?
}

Ele Vahtmäe

Birgot Paavel

Tiit Kutser 


\title{
How much benthic information can be retrieved with hyperspectral sensor from the optically complex coastal waters?
}

\author{
Ele Vahtmäe,* Birgot Paavel, and Tiit Kutser \\ University of Tartu, Estonian Marine Institute, Tallinn, Estonia
}

\begin{abstract}
The Baltic Sea represents an optically complex case 2 water type, where high concentrations of water column constituents limit acquisition of benthic information. Different preprocessing steps were applied to the hyperspectral compact airborne spectrographic imager (CASI) image to extract as much useful benthic information as possible. Atmospheric correction, minimum noise fraction transform, and sun-glint correction were performed to acquire water surface reflectance data. Additionally, a water column removal procedure was applied to acquire bottom reflectance data. Although retrieved CASI water surface reflectance spectra generally matched the magnitudes and shapes of in situ measured spectra, then the applied water column correction algorithm did not yield accurate bottom reflectance spectra. Therefore, both benthic habitat and bathymetry maps were retrieved from the CASI sea surface image data set. An image-based supervised classification method produced a good quality benthic habitat map from the shallow Pakri study area (depth $<3.0 \mathrm{~m}$ ) with an overall accuracy of $80 \%$. A site-specific algorithm was developed for the bathymetry retrieval utilizing a green-yellow CASI band ratio. Validation of the bathymetry map for depths shallower than $4.0 \mathrm{~m}$ revealed an $R^{2}$ value of 0.88 and a root-mean-square error of $0.32 \mathrm{~m}$. The assessment of the benthic substrate detectability limits in the Baltic Sea revealed that, at the wavelength of deepest light penetration (near $570 \mathrm{~nm}$ ), the depth restriction for CASI benthic substrate detection was $7.6 \mathrm{~m}$ for sand, $5.0 \mathrm{~m}$ for green macroalgae, $3.0 \mathrm{~m}$ for higher order vegetation, and $3.1 \mathrm{~m}$ for brown macroalgae. The depth limit to which bathymetric mapping is practical in our study site was estimated to be around 3.5 to $4.0 \mathrm{~m}$. (C) The Authors. Published by SPIE under a Creative Commons Attribution 4.0 Unported License. Distribution or reproduction of this work in whole or in part requires full attribution of the original publication, including its DOI. [DOI: 10.1117/1.JRS.14.016504]
\end{abstract}

Keywords: hyperspectral; CASI; Baltic Sea; benthic habitat; bathymetry; detectability limit.

Paper 190755 received Sep. 26, 2019; accepted for publication Dec. 12, 2019; published online Jan. 6, 2020.

\section{Introduction}

Remote sensing is a widely used method for studying shallow marine and fresh water benthic environments. The method can provide information about the benthic habitats and bathymetry provided that the water is optically shallow. Optically shallow waters occur wherever the reflectance of the bottom can be detected from above the water's surface and are determined by the water depth, optical properties of the water column, and underlying benthos. ${ }^{1}$

Thematic benthic habitat maps are fundamental to characterizing marine systems. ${ }^{2}$ For mapping purposes, habitats are defined as spatially recognizable areas where the physical, chemical, and biological environment is distinctly different from surrounding areas. ${ }^{3}$ The majority of remote sensing studies conducted in optically shallow waters have aimed at mapping the distribution of either single benthic habitat, such as monodominant seagrass beds, ${ }^{4,5}$ or several different benthic habitats, such as heterogeneous communities of seagrasses, coral reefs, and macroalgae. ${ }^{6-18}$ In addition to the spatial distribution, it is important to investigate the temporal dynamics of benthic habitats as changes in the benthic vegetation distribution pattern may indicate changes in the environmental conditions. Several studies have estimated the potential

*Address all correspondence to Ele Vahtmäe, E-mail: Ele.vahtmae@sea.ee 
of remote sensing techniques for detecting changes in the distribution of marine benthic communities taking place over different time periods. ${ }^{19-22}$

The abundance of benthic vegetation, such as canopy cover, biomass or leaf area index (LAI) has been assessed least frequently as the estimation models require extensive field calibration. ${ }^{23-27}$ In recent years, there is also a growing need to better understand the importance of coastal benthic habitats in the global ocean carbon budget. Vegetated coastal habitats, including seagrass and macroalgae beds, mangrove forests, and salt marshes, form highly productive ecosystems, but their contribution to the global carbon budget remains overlooked. ${ }^{28}$ Therefore, some researchers have attempted to investigate the ability of remote sensing technology to quantify not just distribution and abundance but also productivity of coastal benthic vegetation. ${ }^{27,29-31}$

Bathymetry is another important parameter that plays an increasing role in many marine applications (marine spatial planning, navigation, seabed morphology studies, dredging, port facility management, etc.), and remote sensing technology has been used more frequently for the water depth determination. ${ }^{32-38}$

Remote sensing has an increasing potential in studies aimed at retrieving information from the bottom of the water body. However, it is more challenging to acquire spectral information from aquatic benthic environments compared with terrestrial environments. A remote sensing sensor pointed down at the shallow water body can receive light affected by four separate processes. The first process corresponds to light that reaches the sensor after scattering by the atmosphere. In the case of aquatic remote sensing, the total signal received by the remote sensing sensor is highly dominated by radiance contributed by atmospheric scattering processes. ${ }^{39}$ The majority of waters reflect between $2 \%$ and $6 \%$ of downwelling irradiance; ${ }^{40}$ the rest of the signal received by a sensor has been contributed by the atmosphere. Therefore, small inaccuracies in the estimation of the atmospheric component may result in substantial errors in the estimation of the water component.

The second process corresponds to light reaching the sensor after reflection from the airwater interface without entering the water body. This part of the light is referred to as the sun glint. Sun glint, caused by specular reflection of solar radiation on nonflat water surfaces, can be a serious confounding factor for remote sensing of benthic habitats, especially in images with a spatial resolution of $<10 \mathrm{~m} .{ }^{41}$ The presence and amount of sun glint depends on the state of the sea surface, wind speed, sun position, and viewing angle. ${ }^{41-43}$

The third process corresponds to light that penetrates the water surface and interacts with water molecules and other optically active constituents present in the water column, such as phytoplankton, colored dissolved organic matter (CDOM), and particulate matter. ${ }^{44}$ This part of the light does not reach the water bottom and carries information only about the water column properties. The last process corresponds to light that reflects back from the bottom of the water body. Only this last part of light carries information about the benthic substrates and water depth. Hence, atmospheric, water surface, and water column contributions need to be considered and removed to acquire information from the water bottom.

If light enters the water body, it starts to diminish with increasing water depth and benthic habitats become less spectrally separable, as the optical properties of the water column constituents tend to dominate the signal. ${ }^{15}$ The higher the concentration of optically active constituents in the water body, the shorter the distance of light penetration. Optically complex coastal waters of the Baltic Sea are characterized by high concentration of CDOM ${ }^{45}$ suspended particles, ${ }^{46}$ and phytoplankton. ${ }^{47}$ High concentrations of those water column constituents restrict the light reaching the water bottom even at relatively shallow depths. Therefore, acquiring benthic information from the Baltic Sea is limited. The main goal of this study was to investigate how much benthic information can be retrieved from a hyperspectral sensor in the complex Baltic Sea waters using simple empirical and semianalytical models. The more specific objectives of the study were defined accordingly as follows.

1. To perform different image processing levels to correct for atmospheric, sun glint, and water column contributions and assess the performance of each processing level.

2. To assess the potential limits to acquire benthic information from such a complex water body.

3. To generate benthic habitat and bathymetry maps from a hyperspectral compact airborne spectrographic imager (CASI) single-image data set. 


\section{Materials and Methods}

\subsection{Study Site}

The study site was located in the northern coast of Estonia, the Gulf of Finland, the Baltic Sea (Fig. 1). The study area encompassed $\sim 200 \mathrm{~km}^{2}$ covering the coast of the mainland and two Pakri islands-Suur Pakri and Väike Pakri. The islands are separated from the mainland to the south by the shallow Kurkse Strait. The Pakri islands and surrounding marine area belong to the Natura 2000 network, which is the European network of protected areas.

The water depth in the study area remains generally below $5 \mathrm{~m}$, but water depth may reach near $100 \mathrm{~m}$ in some parts of the open sea. Higher plants, such as Potamogeton pectinatus, Zannichellia palustris, and Zostera marina, as well as charophytes dominate the soft sandy substrate found in the sheltered areas between islands and between the mainland and islands. Hard substrates (rock, boulders, stones, etc.) are found in more exposed areas dominated by either brown algae Fucus vesiculosus or filamentous green algae Cladophora glomerata communities.

\subsection{In Situ Field Sampling}

Ground reference data were collected from May 30 to June 3, 2016, at the same time as the remote sensing data collection. Underwater video records for characterizing benthic habitats were collected from almost 200 field stations. The locations of the field stations were determined previously using aerial photographs from the public web map application of the Estonian Land Board. The video analysis method described in Ref. 48 was used to estimate the substrate type, the total coverage of benthic vegetation, and the coverage of visually distinguishable vegetation species. Coordinates of each field station were recorded by the global positioning system. Bathymetry was measured with the boat echo sounder.

Above water reflectance measurements were acquired using two Ramses (TriOS) hyperspectral sensors. Measurements were taken in 10 field stations above homogeneous substrate or vegetation patches estimated visually from the boat. Multiple reflectance measurements (5 to 10) were performed in each field station, from which the average spectrum was calculated. Above water reflectance measurements provided ground reference for the assessment of image preprocessing steps. The Ramses two-sensor system included irradiance and radiance sensors. The irradiance sensor was used to measure downwelling spectral irradiance $E_{d}\left(\mathrm{~W} \mathrm{~m}^{-2} \mathrm{~nm}^{-1}\right)$, and the radiance sensor was used to measure upwelling spectral radiance $L_{u}\left(\mathrm{~W} \mathrm{~m}^{-2} \mathrm{~nm}^{-1} \mathrm{sr}^{-1}\right)$. Above water remote sensing reflectance was calculated as the ratio of $L_{u} / E_{d}$. Ramses remote sensing reflectance was multiplied by the $Q$-factor, which converted it to the irradiance reflectance, making it thereafter comparable to the outcome of the atmospheric correction.

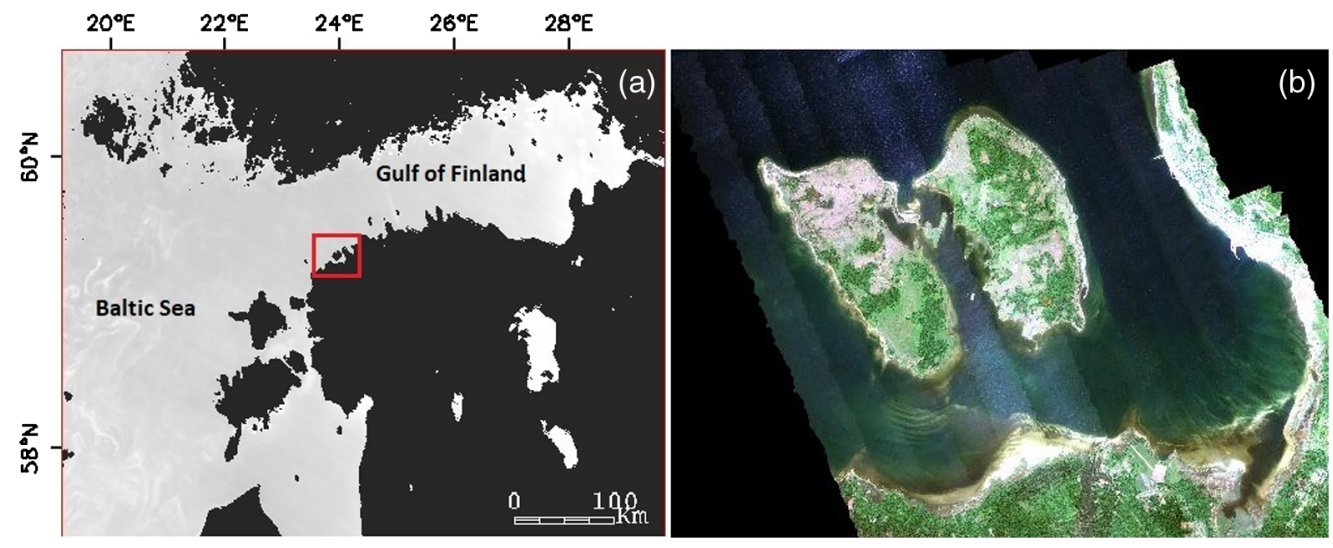

Fig. 1 Location of the (a) study area in the northern coast of Estonia, the Gulf of Finland, the Baltic Sea and (b) study area imaged by the CASI hyperspectral sensor on May 31, 2016. 
The $Q$-value may range from 3 to 6 steradians, ${ }^{49}$ but as defining its value was outside of the scope of the current study, the $Q$-factor was considered equal to $\pi$.

Depth profiles for downwelling irradiance $\left(E_{d}\right)$ were acquired with Ramses radiometers in four field stations around Pakri islands on the same day as the image collection. Ramses was lowered through the water column and measurements taken every $0.5 \mathrm{~m}$ from the surface to the depth of $2.5 \mathrm{~m}$. The underwater $E_{d}$ depth profiles were used to calculate the diffuse downwelling attenuation coefficient $\left(K_{d}\right)$, which was required to perform the water column correction (WCC). Water samples were collected concurrently with depth profiles, which were later analyzed for the concentrations of $a_{\mathrm{CDOM}}\left(\mathrm{m}^{-1}\right)$, total suspended matter $\left(\mathrm{TSM}, \mathrm{g} \mathrm{m}^{-3}\right)$, and chlorophyll a $\left(\mathrm{Chl}-\mathrm{a}, \mathrm{mg} \mathrm{m}^{-3}\right)$. Laboratory water sample analyses are described in Ref. 50.

\subsection{Airborne Remote Sensing}

Airborne hyperspectral imagery was acquired on May 31, 2016, over the Pakri marine area with a CASI-1500 sensor produced by Itres, Canada (Fig. 1). The data collection was conducted by the Latvian Institute for Environmental Solutions (IES). CASI sensor covers a spectral range between 367 and $1045 \mathrm{~nm}$. Bandwidths of the CASI-1500 sensor are programable, and different bandwidths were selected to optimize the signal-to-noise ratio (SNR) across the entire spectrum. The sensor has lower sensitivity in the blue and near-infrared (NIR) regions of the spectrum, and broader $(\sim 10 \mathrm{~nm})$ bandwidths were selected for that region. Narrower bandwidths $(\sim 5 \mathrm{~nm})$ were selected for the 550- to 750-nm spectral range. A total of 93 spectral bands were used for the data collection.

Altogether 12 flight lines were collected from the Pakri study area. The data were collected at the altitude of $2100 \mathrm{~m}$, resulting in $1.0 \mathrm{~m}$ spatial resolution. Unfortunately, image quality suffered from brightness unevenness, resulting in the visible contrast in the central region of each flight line.

\subsection{Image Processing}

A critical step in remote sensing data analysis is the preprocessing of images. Radiometric correction and geo-correction of the CASI data were conducted by the IES. After that, ENVI ${ }^{\circledR}$ software (Research Systems Inc.) was used to apply subsequent preprocessing procedures: (1) atmospheric correction, (2) minimum noise fraction (MNF) transform, (3) glint correction, and (4) WCC.

\subsubsection{Atmospheric correction}

The atmospheric contribution was removed from the CASI data using the fast line-of-sight atmospheric analysis of spectral hypercubes (FLAASH) module in ENVI. During the atmospheric correction process, the sea surface reflectance data were retrieved from the at-sensor radiance data. FLAASH is a first-principle atmospheric correction software package that is based on the MODTRAN4 radiation transfer code that was developed by the Air Force Phillips Laboratory and Spectral Sciences, Inc. ${ }^{51}$ The atmospheric model for FLAASH processing was defined as mid-latitude summer, and the aerosol model was defined as maritime. Visibility values for FLAASH were adjusted in the way that the retrieved reflectance values in the NIR spectral region over the optically deep water approached zero.

\subsubsection{Minimum noise fraction transform}

The MNF method was applied to the atmospherically corrected images to reduce the inherent noise of hyperspectral data. Hyperspectral remote sensing sensors are characterized by low SNR because of the fewer number of photons captured by each detector due to the narrower width of the spectral channels. ${ }^{52}$ In recent years, the issue of noise reduction has been considered by many researchers and various spectral smoothing methods have been proposed, ${ }^{53-55}$ among them is the MNF method. ${ }^{56}$ The MNF transform is a linear transformation that consists of two separate steps 
described by Luo et al. ${ }^{55}$ : (1) use the noise covariance matrix to decorrelate and rescale the noise in the data (noise whitening). In this way, the noise has unit variance and no band-to-band correlations. (2) Perform a standard PCA transform to the noise-whitened data. Following MNF transform, flight lines were mosaiced together.

\subsubsection{Glint correction and land mask}

The deglinting procedure was applied to the atmospherically and MNF corrected image. The deglinting model proposed by Hedley et al. ${ }^{41}$ was used for the sun-glint removal. The method relies on two assumptions: (1) the NIR reflectance over water is caused solely by sun glint and (2) the magnitude of NIR reflectance is linearly related to the magnitude of glint reflectance in each of the visible spectral bands. ${ }^{18}$ This method establishes linear relationships between NIR and visible bands using linear regression based on a homogeneous sample of the sun-glinted pixels over optically deep water: ${ }^{41}$

$$
R_{\text {deglinted }}=R_{\text {initial }}-\operatorname{slope}\left(R_{\mathrm{NIR}}-\mathrm{MIN}_{\mathrm{NIR}}\right),
$$

where $R_{\text {deglinted }}$ is the glint corrected reflectance, $R_{\text {initial }}$ is the initial reflectance, $R_{\mathrm{NIR}}$ is the reflectance in the NIR waveband, which in our case was $897 \mathrm{~nm}, \mathrm{MIN}_{\mathrm{NIR}}$ is the minimum reflectance value for the NIR waveband determined from the homogeneous sample set, and slope is the regression slope established between the NIR waveband and each visible waveband.

After sun-glint removal, land pixels were masked out from the image using the NIR spectral band, as this spectral region shows the most contrast between land and water pixels.

\subsubsection{Water column correction}

The last step in the image preprocessing was WCC. This correction step allows for retrieving bottom reflectance from water surface reflectance. Various WCC methods have been proposed in the literature. Zoffoli et al. ${ }^{44}$ provided a comprehensive overview of different methods and proposed to group them according to their methodological approach as follows: band combination algorithms, model-based algebraic algorithms, and optimization/matching algorithms.

The best WCC method to be chosen depends on the study site complexity, sensor characteristics, mapping purposes, and access to in situ data. ${ }^{34,44}$ Band combination algorithms do not retrieve actual substrate reflectance spectra; instead, they produce an index. These algorithms can be used when the study aims to solely produce a bottom classification map. ${ }^{44}$ We were interested in retrieving substrate reflectance spectra, and the simple model-based semianalytical method proposed by Maritorena et al. ${ }^{1}$ was used for the water column removal. This method requires limited numbers of in situ measurements as model inputs.

Maritorena WCC model. Maritorena developed a model for retrieving water surface reflectance in the shallow waters: ${ }^{1}$

$$
R_{w}(0-)=R_{\infty}+\left(R_{b}-R_{\infty}\right) \exp \left(-2 K_{d} z\right)
$$

where $R_{w}(0-)$ is the reflectance just below the water surface, $R_{\infty}$ is the reflectance of optically deep water just below the water surface, $R_{b}$ is the bottom reflectance, $K_{d}$ is the diffuse downwelling attenuation coefficient of the water column, and $z$ is the water depth. The model assumes horizontal and vertical homogeneity of water optical properties throughout the study area. ${ }^{1}$ The model was inverted to derive bottom reflectance from water surface reflectance measurements:

$$
R_{b}=\frac{R_{w}-R_{\infty}}{\exp \left(-2 K_{d} z\right)}+R_{\infty}
$$


Since the Maritorena model was developed for reflectance just below the water surface $\left[R_{w}(0-)\right]$, CASI above water surface reflectance $\left[R_{w}(0+)\right]$ was converted to below water surface reflectance using the approximation proposed by Mobley: ${ }^{57}$

$$
\frac{R_{w}(0+)}{R_{w}(0-)}=0.544
$$

Incorporating the latter term into Eq. (3), yields

$$
R_{b}=\frac{\frac{R_{w}^{\text {CASI }}}{0.54}-\frac{R_{\infty}^{\text {CASI }}}{0.54}}{\exp \left(-2 K_{d} z\right)}+\frac{R_{\infty}^{\text {CASI }}}{0.54} .
$$

Several optically deep water spectra were selected from the CASI image, and an average spectrum was calculated. It was used as an input to the WCC algorithm to represent the optically deep water spectra. The WCC algorithm requires two main variables: water depth $(z)$ data for every image pixel and water column attenuation characteristics $\left(K_{d}\right)$. For the water depth determination, a site-specific algorithm was developed as described in Sec. 2.6. $K_{d}$ was calculated from in situ Ramses $E_{d}$ measurements at two depths $z_{1}$ and $z_{2}$ according to Ref. 39:

$$
K_{d}=-\frac{1}{\Delta z} \ln \left[\frac{E_{d}\left(z_{2}\right)}{E_{d}\left(z_{1}\right)}\right],
$$

in which $\Delta z$ is the difference in depth, $E_{d}\left(z_{1}\right)$ is the downwelling spectral irradiance at depth $z_{1}$, and $E_{d}\left(z_{2}\right)$ is the downwelling spectral irradiance at depth $z_{2}$, where $z_{2}$ is the measurement depth and $z_{1}$ is a reference depth closer to the water surface.

A maximum depth in which a submerged bottom can be detected by optical remote sensing exists. ${ }^{44}$ With the knowledge of $K_{d}$ and the availability of substrate reflectance spectra, it is possible to estimate depth limits to which the remote sensing sensor can detect different substrates in the given water body. Following Refs. 1, 15, and 18, the detectability limits of selected substrates for our study site were computed:

$$
z=\frac{1}{2 K_{d}} \ln \left(\frac{R_{B}-R_{\infty}}{R_{\infty}^{\mathrm{SD}}}\right),
$$

where $R_{B}$ is the substrates' reflectance spectra, $R_{\infty}$ is the average optically deep water reflectance spectra just below the water surface, $R^{\mathrm{SD}}$ is the standard deviation of reflectance spectra collected within a homogeneous optically deep water area, and $K_{d}$ is calculated by Eq. (5). The substrate's reflectance spectra collected over the years from different parts of the Baltic Sea were taken from our spectral library presented in Ref. 58. The same substrate's spectra were also used for the evaluation of the performance of WCC.

\subsection{Benthic Habitat Classification}

Collected underwater video records were analyzed for sediment properties, as well as for benthic vegetation species and coverage. As a result, a benthic habitat classification scheme in which prevailing habitat types were grouped into classes representing the pattern of the ecosystem was developed. Seven benthic classes were defined and labeled as (a) bare substrate, (b) filamentous green algae, (c) sparse higher order vegetation, (d) dense higher order vegetation, (e) charophytes, (f) brown macroalgae, and (g) deep water (Table 1 and Fig. 2). Red macroalgae were identified in some field stations, but as they were found in low quantities they were excluded from the classification scheme. The classification scheme for the current study was defined based on the dominant class. If, for example, the coverage of brown macroalgae in a particular sampling point was estimated to be $60 \%$ and the coverage of red macroalgae $20 \%$, it was considered a point belonging to the brown macroalgae class. We cannot say that red macroalgae were completely absent in the Pakri study area, but they were not dominant in our sampling sites.

A supervised classification procedure, which automatically divides all image pixels into previously defined habitat classes, was applied to the imagery. Information acquired by underwater 
Table 1 The species and sediment composition contained within each of the seven benthic habitat classes.

\begin{tabular}{ll}
\hline \hline Habitat classes & \multicolumn{1}{c}{ Composition } \\
\hline Bare substrate & Sand or gravel, total vegetation cover $<10 \%$ \\
Filamentous green algae & $\begin{array}{l}\text { Pebble and rocks with green filamentous algae } \\
\text { (prevailing species Cladophora sp., Enteromorpha sp.) }\end{array}$ \\
Sparse higher order vegetation & $\begin{array}{l}\text { Sand or mud, total vegetation coverage }<30 \%, \\
\text { (prevailing species Potamogeton sp., Zostera sp.) }\end{array}$ \\
Dense higher order vegetation & $\begin{array}{l}\text { Sand or mud, total vegetation coverage }>30 \%, \\
\text { (prevailing species Potamogeton sp., Zostera sp.) }\end{array}$ \\
Charophytes & $\begin{array}{l}\text { Sand or mud with charophytes } \\
\text { Brown macroalgae }\end{array}$ \\
Reep water & $\begin{array}{l}\text { (prevailing species Fucus sp.) } \\
\text { Water depth }>3 \mathrm{~m}\end{array}$ \\
\hline \hline
\end{tabular}
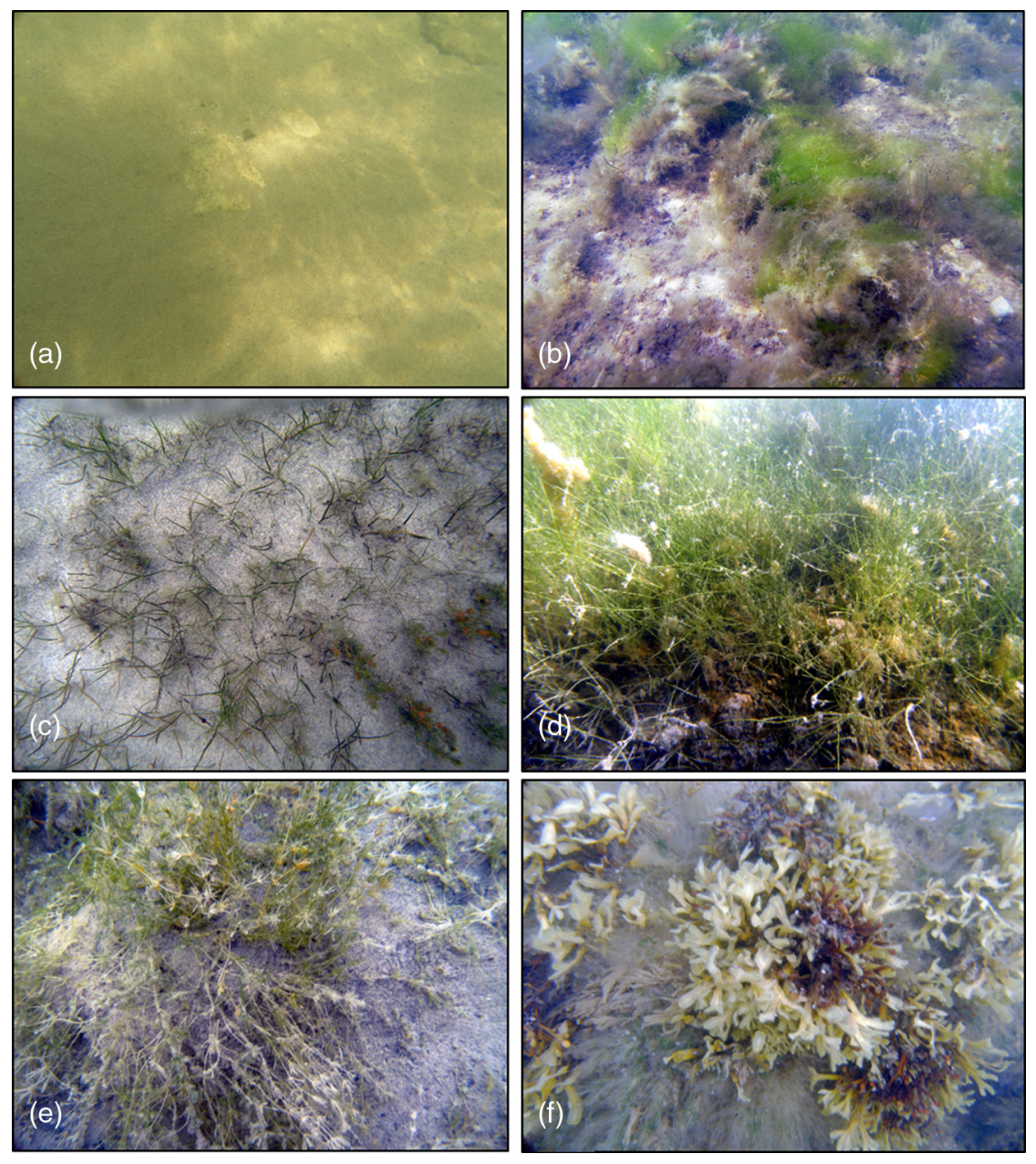

Fig. 2 Classes defined for benthic habitat classification: (a) bare substrate, (b) filamentous green algae, (c) sparse higher order vegetation (vegetation $<30 \%$ ), (d) dense higher order vegetation (vegetation $>30 \%$ ), (e) charophytes, and (f) brown macroalgae. 
video records was used for selecting training regions of interest (ROIs) for supervised classification. The quality of the classification results was assessed by the quantitative process of accuracy assessment utilizing ground reference data from video records. The ground reference data used for the validation of classified maps were nonoverlapping from the data used for training the classification algorithms.

\subsection{Bathymetry}

In situ water depth measurements were used for the site-specific bathymetry algorithm development proposed by Stumpf et al. ${ }^{33}$ The basic premise of the model is that, because water absorptivity is wavelength dependent, the upwelling radiance measured in a spectral band experiencing greater absorption will be less than that measured in a band with weaker absorption. ${ }^{59}$ Thus with increasing water depth, reflectance values decrease proportionally faster in a band with greater absorption and slower in a band with weaker absorption. As depth increases, the reflectance ratio of low absorption band to high absorption band should show an increase and need to be scaled to the actual depth according to Ref. 33:

$$
Z=m_{1} \frac{\ln \left[n R_{w}\left(\lambda_{i}\right)\right]}{\ln \left[n R_{w}\left(\lambda_{j}\right)\right]}-m_{0},
$$

where $Z$ is a depth, $m_{1}$ and $m_{0}$ are obtained from regression of the linear equation, $R_{w}$ is the reflectance value for bands $i$ and $j$, and $n$ is a fixed constant to assure positive logarithm and linear response with depth. The $n$ value of 1000 was used in this study.

In our previous study, ${ }^{37}$ different band combinations of Hyspex hyperspectral sensors were tested to specify spectral regions most suitable for the bathymetry mapping in the Baltic Sea conditions. The study showed that the ratio of green band to yellow band achieved the best correlations with measured water depths. Therefore, in this study, we concentrated on the green/yellow spectral regions and defined specific CASI bands, which allowed for the best correlation with the water depth. The best correlation was achieved using a wavelength ratio of $520 / 608 \mathrm{~nm}$. In addition, Vahtmäe and $\mathrm{Kutser}^{37}$ showed that the best processing level for bathymetry retrieval was imagery with atmospheric correction. For that reason, the bathymetry model was applied to the atmospherically and MNF corrected CASI image.

The retrieved bathymetry was smoothed with a $3 \times 3$ low-pass filter to reduce noise, which would otherwise potentially reduce the accuracy of WCC.

\section{Results}

\subsection{Sea Surface Reflectance}

Sea surface reflectance was retrieved from the CASI hyperspectral sensor after completing three image correction steps: atmospheric correction, MNF transform, and glint correction. The performance of those preprocessing steps was assessed by comparing the spectrum of the corrected image pixel with field spectral measurements of the corresponding pixel taken using the Ramses spectrometer. Some selected spectra of the CASI preprocessed spectra and Ramses in situ measurements are shown in Fig. 3.

In general, reflectance spectra derived from the CASI sensor captured the overall spectral shapes of spectra measured with the Ramses spectrometer. The surface reflectance spectra retrieved after applying atmospheric correction (Fig. 3, casi_1) contained significant levels of noise. Brighter spectra (e.g., sand) contained lesser amounts of noise compared with the darker spectra (e.g., optically deep water) as brighter objects exhibit higher signal levels. The MNF transformation produced much smoother spectra (Fig. 3, casi_2). This shows that MNF transform may help to remove the residual noise from hyperspectral data.

Glint correction reduced reflectance for all visible bands (Fig. 3, casi_3). In general, glint corrected spectra became more similar to in situ measured Ramses spectra in absolute values than atmospherically corrected spectra. Nevertheless, for example, in situ measured green macroalga spectra [Fig. 3(c)] showed higher reflectance values than glint corrected spectra. 
(a)

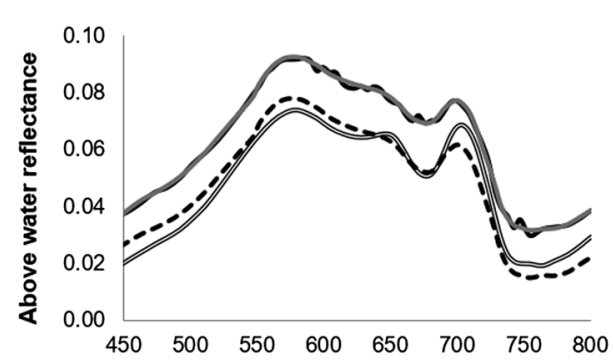

(c)

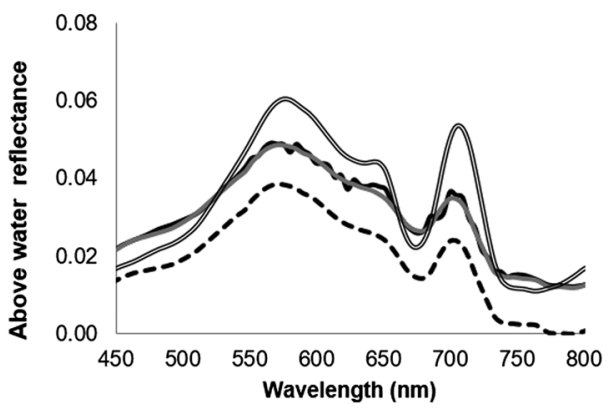

(b)

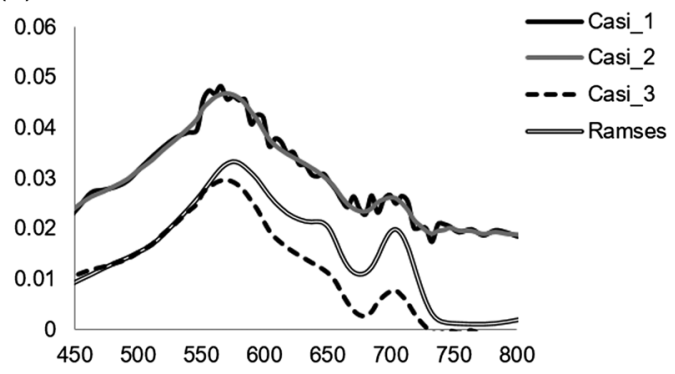

(d)

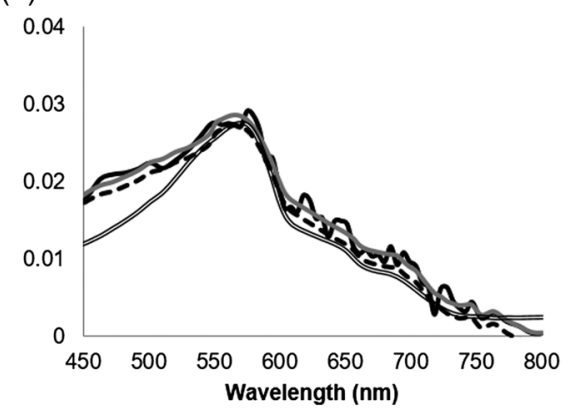

Fig. 3 Comparisons of Ramses ground-truth spectra with corresponding different level corrected CASI spectra: (casi_1) atmospherically corrected spectra; (casi_2) atmospherically and MNF corrected spectra; and (casi_3) atmospherically, MNF and glint corrected spectra. (a) Sand $0.4 \mathrm{~m}$, (b) brown macroalgae $1.0 \mathrm{~m}$, (c) green macroalgae $0.5 \mathrm{~m}$, and (d) optically deep water.

The difference may be conditioned from the high spatial heterogeneity characteristic of Estonian coastal waters, namely, as the CASI pixel area is $1 \mathrm{~m}^{2}$, different vegetation species as well as substrate may contribute to the total signal in heterogeneous areas. The Ramses measurement area is only a few $\mathrm{cm}^{2}$ (depending on the measurement distance). Due to the different measurement areas, reflectances captured by different sensors do not always match, even though measured in the same location.

Some negative values below 720 to $750 \mathrm{~nm}$ were retrieved after the glint correction procedure. The reason for this is that the method used for the sun-glint removal assumes a negligible water-leaving signal in the NIR spectral region. In practice, however, there is always some "residual" radiance in the NIR part of the spectrum and the NIR signal can be significant if the water is optically shallow. ${ }^{7,41,60}$ Therefore, in the current case, it can be assumed that some benthic NIR-reflectance contributed to the water-leaving NIR signal and caused overcorrection of reflectance values.

In addition, neither atmospheric nor glint correction managed to correct blue wavelengths of the CASI optically deep water spectra. Shorter wavelengths (below $520 \mathrm{~nm}$ ) of optically deep water remained under-corrected as shown in Fig. 3(d).

\subsection{Diffuse Attenuation Coefficient}

$K_{d}$ was calculated from in situ Ramses vertical profile measurements [Eq. (6)]. Vertical profiles were measured at four field stations, and for each station $K_{d}$ values along the water column were averaged. Finally, an average $K_{d}$ value between all profiles was obtained (Fig. 4). $K_{d}$ values increased exponentially beyond $700 \mathrm{~nm}$ due to the increasing water absorption. CDOM absorbs strongly in the blue spectral region and Chl-a in the blue and red spectral regions, which resulted in increased $K_{d}$ values in those spectral ranges.

It is seen that $K_{d}$ spectra had low variance throughout all sampled sites, suggesting that the water optical properties were relatively constant over the study site (Table 2). The concentrations of water column constituents clearly characterized a case 2 water type. CDOM concentrations were similar to the open parts of the Baltic Sea. TSM concentrations were rather high, probably 


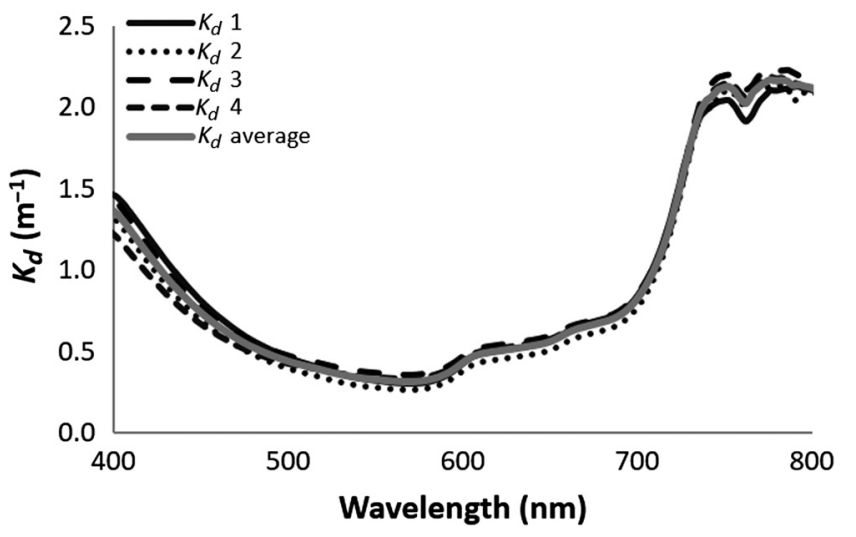

Fig. 4 Downwelling diffuse attenuation coefficients, $K_{d}\left(\mathrm{~m}^{-1}\right)$, derived from $E_{d}$ in-water profiles at four field stations around the Pakri marine area.

Table 2 Water column optical constituents for Pakri marine area field sites.

\begin{tabular}{lcc}
\hline \hline & Average & Range \\
\hline$a_{\mathrm{CDOM}}(440)\left(\mathrm{m}^{-1}\right)$ & 0.59 & 0.52 to 0.64 \\
$\mathrm{TSM}\left(\mathrm{g} \mathrm{m}^{-3}\right)$ & 7.23 & 5.70 to 9.00 \\
$\mathrm{Chl}-\mathrm{a}\left(\mathrm{mg} \mathrm{m}^{-3}\right)$ & 1.28 & 0.58 to 1.78 \\
\hline \hline
\end{tabular}

due to resuspension of sediments by the wind. Chl-a concentrations were also typical of the Baltic Sea waters, remaining below the bloom limit $\left(5 \mathrm{mg} / \mathrm{m}^{3}\right)$.

\subsection{Benthic Substrate Detectability Limits}

Detectability limits [Eq. (7)] were calculated for five main benthic substrate classes present in the Baltic Sea: red macroalgae, brown macroalgae, green macroalgae, higher order vegetation, and bare substrate. Each class was represented by species widely spread over the Baltic Sea and/or considered a key species in the Baltic Sea: Furcellaria lumbricalis (red macroalgae), Fucus vesiculosus (brown macroalgae), Cladophora glomerata (green macroalgae), and Potamogeton pectinatus (higher order vegetation). Bare substrate was represented by a sand spectrum. End-member spectra of the substrates were taken from our spectral library. If the end-member library contained several measurements per species, then the mean spectrum was calculated.

Figure 5 shows detectability limits for selected benthic species at given water attenuation properties (expressed as $K_{d}$, Fig. 4). It is seen that invalid values were retrieved for almost all substrates in cases of blue wavelengths (below $520 \mathrm{~nm}$ ) while using Eq. (7) for detectability limits calculations. This was caused by the fact that the optically deep water spectrum, used in the calculation, was extracted from the CASI sea surface reflectance image. However, blue wavelengths of this extracted spectrum [Fig. 3(d)] exhibited higher spectral values than end-member spectra as they were under-corrected during atmospheric correction.

The depth limits for benthic substrate detection varied depending on the magnitude of substrate reflectance. The substrate with the highest reflectance (e.g., sand) was discernible from deep water at the furthest depths. At the wavelength of deepest light penetration (near $570 \mathrm{~nm}$ ), the depth restriction for CASI benthic substrate detection extended to $7.6 \mathrm{~m}$ for sand, $5.0 \mathrm{~m}$ for green macroalgae Cladophora, $3.0 \mathrm{~m}$ for higher order vegetation Potamogeton, and $3.1 \mathrm{~m}$ for brown macroalgae Fucus. In the red spectral region, the maximum depth of detection for most substrates remained around 2 to $3 \mathrm{~m}$ and in the NIR spectral region around $1 \mathrm{~m}$. 

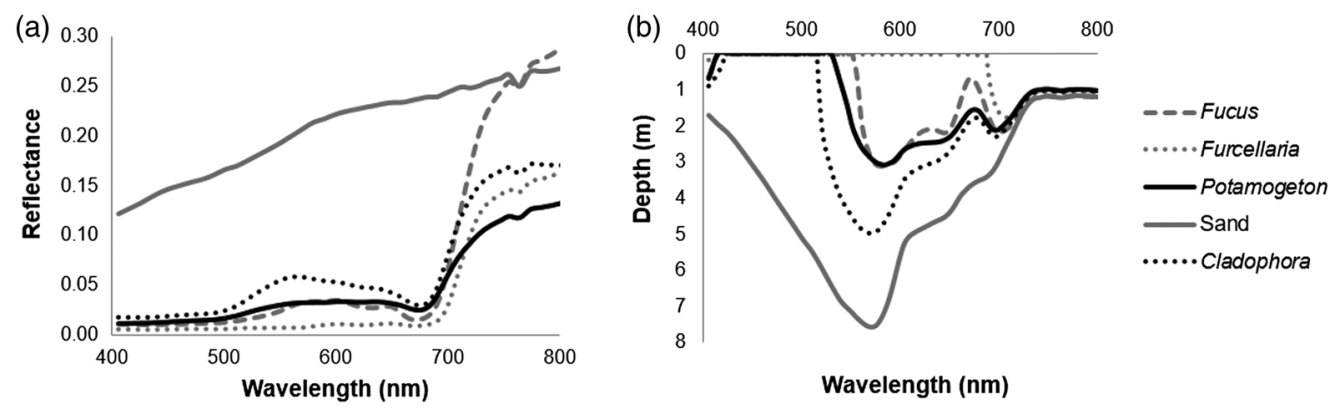

Fig. 5 (a) End-member spectra of selected substrates used in the detectability calculations and (b) the depth at which the CASI sensor can no longer differentiate a substrate from optically deep water. Refer to Fig. 4 for an average $K_{d}$.

Reflectance values of red macroalga Furcellaria remained lower than an average optically deep water spectrum almost throughout the entire spectrum, providing invalid results in the case of using Eq. (7).

\subsection{Bathymetry Mapping}

Altogether, 175 in situ measured depth points from a depth range of 0 to $4 \mathrm{~m}$ were collected from the study area. Half of the measured depth points were used for the calibration and half for the validation of the bathymetry model. Figure 6 displays a scatterplot comparison of modeled water depths retrieved by the bathymetry model versus in situ measured depths. The validation of the derived bathymetry map revealed a correlation coefficient $\left(R^{2}\right)$ value of 0.88 with a root-meansquare error (RMSE) of $0.32 \mathrm{~m}$.

The water depth map obtained by the bathymetry model across the study site is shown in Fig. 7. Shallower areas (depth under $3 \mathrm{~m}$ ) were found mostly in between two Pakri islands and south of islands. Some interesting features included, for example, sand dunes fringing the coast of the mainland and sand waves between Western Island and the mainland in 0.5 to $2 \mathrm{~m}$ of water. Water depth increased fast in the seaside coasts of the Pakri islands.

Sudden depth variations visible in the bathymetry map (Fig. 7) were caused by across-track brightness gradients between multiple CASI flight lines. However, these artifacts were not important from the benthic habitat mapping point of view as they occurred in waters too deep for habitat mapping. Such brightness artifacts can be compensated for or at least reduced by applying brightness gradient correction methods such as the cross-track correction procedure in ENVI. The procedure should be applied to the individual radiometrically corrected flight lines prior to geocorrection. In the current case, CASI data were received from the IES that were

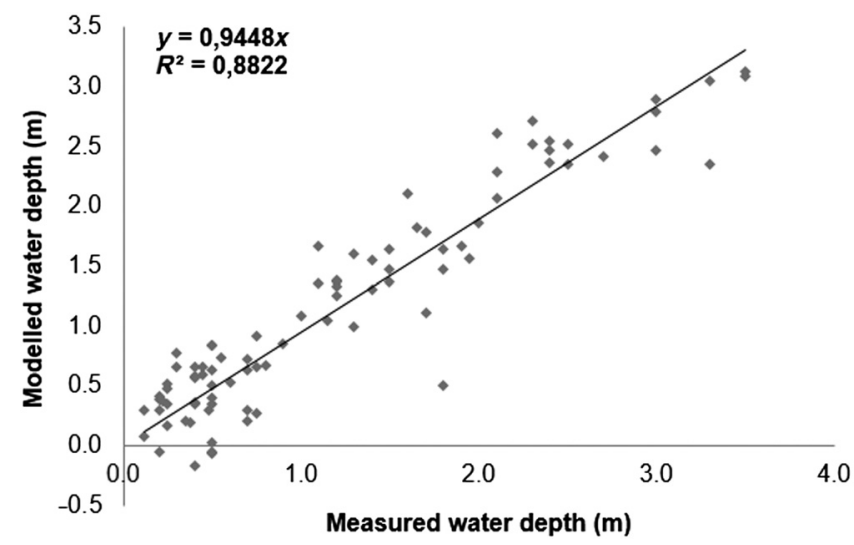

Fig. 6 Comparison of modeled water depths obtained by Stumpf et al. bathymetry model and in situ measured depths. 

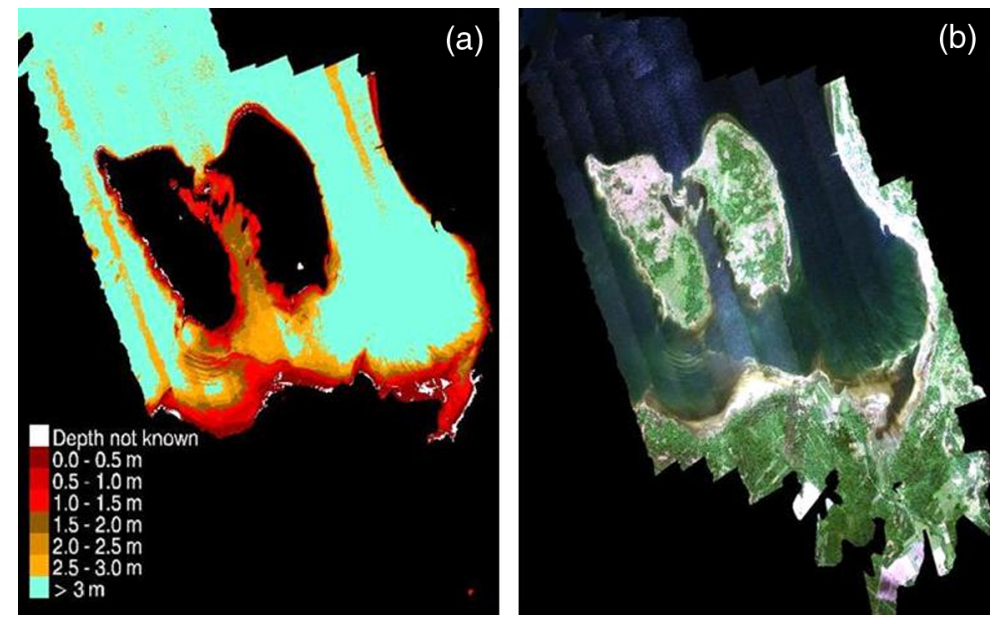

Fig. 7 Water depth map of the Pakri marine area obtained by Stumpf et al.: (a) bathymetry model from the atmospherically and MNF corrected CASI image and (b) CASI true color image from the Pakri study area.

already geometrically corrected. Therefore, the cross-track correction procedure was not applied to the data. Some negative depth values [marked with white in Fig. 7(a)] were also retrieved by the bathymetry model. These areas were mostly located in extremely shallow $(<0.1 \mathrm{~m})$, near-coastal water.

\subsection{Retrieved Bottom Reflectance}

The performance of the WCC was evaluated by comparing the corrected spectra with measured substrates spectra from our spectral library (Fig. 8). The lack of substrate reflectances measured in situ in the study area impeded a quantitative estimation of WCC accuracy. Therefore, we are not able to say whether the overall magnitude of retrieved reflectance values was in agreement with the actual substrate reflectance spectra. Generally, the application of WCC increased reflectance of substrate spectra compared with the surface spectra. Our results showed that there was a closer agreement between end-member and WCC spectra in the case of shallower depths. Magnitudes of WCC reflectance spectra started to increase with increasing depth [Fig. 8(a)]. In addition, negative values in blue and red wavelengths were retrieved in the case of benthic vegetation at depths over $2 \mathrm{~m}$.

To enable better the comparison of spectral shapes, reflectance spectra were standardized based on the mean and standard deviation of the spectra [Fig. 8(b)]. Spectral shapes of bottom spectra retrieved by removing water column effects over green macroalgae (Cladophora sp.) and charophytes (Chara sp.) were consistent with end-member spectra-Chara displaying flatter green peaks compared with Cladophora. Sand end-member spectra increased in reflectance from 450 to $700 \mathrm{~nm}$ without showing any remarkable absorption features, while retrieved CASI sand spectra exhibited a chlorophyll absorption feature near $675 \mathrm{~nm}$. Spectral shapes of retrieved higher order vegetation and corresponding end-member Potamogeton differed from each other to some extent. Reflectance maxima of in situ measured Potamogeton was shifted toward longer wavelengths $(630 \mathrm{~nm})$ compared with WCC spectra, which showed reflectance maxima near $570 \mathrm{~nm}$. Shapes of retrieved brown algae spectra did not correspond to end-member Fucus spectra. Fucus exhibits peaks near 600 and $650 \mathrm{~nm}$ and a shoulder near $580 \mathrm{~nm}$, whereas retrieved brown algae spectra, similar to green algae, displayed reflectance maxima near $570 \mathrm{~nm}$ and a distinctive drop in reflectance from 570 to $680 \mathrm{~nm}$.

Our results showed that the Maritorena WCC method was unsuccessful for sites deeper than $2 \mathrm{~m}$. In addition, some vegetation spectra (e.g., brown algae, higher order vegetation) were not retrieved correctly with the current WCC method even in very shallow water $(<1 \mathrm{~m})$. This suggested that the WCC method was not very useful in optically complex waters, and it was better to use above water reflectance imagery for benthic habitat mapping. 

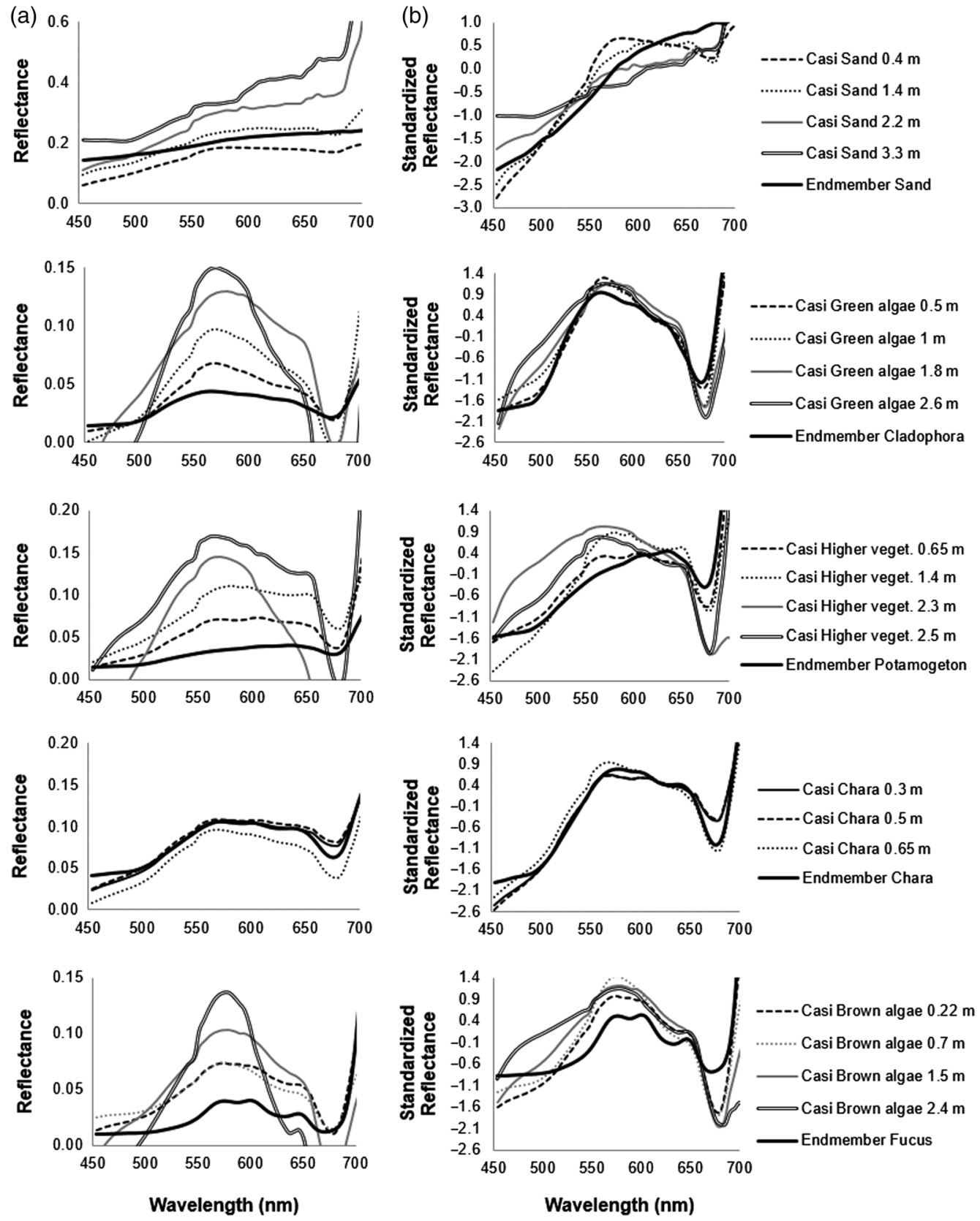

Fig. 8 Reflectance spectra of different substrates at varying water depths extracted from the water column corrected CASI image and corresponding endmember spectra from our spectral library. Absolute reflectance values are displayed in (a) and standardized reflectance values in (b).

\subsection{Benthic Habitat Mapping}

Previous studies ${ }^{16,61}$ have shown that the spectral signal of the same bottom type varies depending on the water depth. Therefore, training ROIs for each benthic habitat class were selected from different water depths.

We used a two-level classification approach. In the first classification step, bare substrate (sand, gravel, limestone, etc.) was differentiated from benthic vegetation and deep water using a minimum distance (MD) classification algorithm. This was performed by generating 13 initial supervised classes (different bottom types at different depths), which were later merged into the two habitat classes of interest (bare substrate and vegetated bottoms). It was relatively straightforward to delineate bare substrate as sand exhibited comparatively brighter spectra than vegetation (Fig. 5). The resulting bare substrate class was masked out from the CASI image. 
As a second step, a new classification procedure was applied to divide vegetated habitats into more detailed classes. Once again supervised classification algorithms, such as MD, maximum likelihood, spectral angle mapper (SAM), etc., were tested. The SAM classification algorithm provided the best result in vegetation mapping as indicated by the initial accuracy assessment. Therefore, it was used in the final classification.

ROIs for each vegetation class were selected from multiple depths considering the depth distribution limits of each substrate class. For example, during the field studies, charophytes were found only in shallower depths and ROIs for the "charophytes" class were selected from depths of $0.2,0.5$, and $1.0 \mathrm{~m}$. At the same time, higher order vegetation was found from broader depth limits, and ROIs for this class were selected from depths of 0.5, 1.0, 1.5, and $2.5 \mathrm{~m}$. The amount of ROIs was gradually increased for those classes, which showed significant confusion with other classes after initial classification. Altogether, 32 training ROIs were used (each ROI corresponds to one pixel, $1 \mathrm{~m}^{2}$ ), which generated 32 habitat classes. Finally, each habitat class at various water depths was merged into the single habitat class, resulting in the water depth-independent benthic habitat map. The benthic habitat map obtained after the two-level classification is presented in Fig. 9.

The classification results showed that the bare substrate was widespread in the area between the Pakri islands and mainland, alternating with dense and sparse higher plants communities. Dense higher vegetation was also mapped between two Pakri islands, mostly in the depths over $1.5 \mathrm{~m}$. Charophytes were found in shallower waters between islands and on soft sandy shores near the coast. Field studies indicated that Charophytes were often covered with rather dense filamentous green algae, particularly on the coast of the mainland. Therefore, it is not surprising that these areas were classified as filamentous green algae by the classification algorithm. Brown algae were estimated to occur mainly on the outer sides of the Pakri islands.

The performance of the classification was assessed using the confusion matrix method, where classified benthic habitats were compared with in situ observed benthic habitat classes. 166 field control points ( $<3 \mathrm{~m}$ water depth) were used for the accuracy assessment, resulting in the overall accuracy of $80 \%$ (Table 3 ).

The confusion matrix method produces also producer and user accuracies, which report individual class accuracies (Table 3). The lowest user accuracy was encountered for the class "sparse higher vegetation" (50\%), meaning that only half of image pixels classified as "sparse higher vegetation" were actually this habitat class and another half belong to some other habitat class. It also means that this class was the most overestimated in the Pakri study area. The lowest producer accuracy was identified for the class "brown macroalgae" $(60 \%)$, which means that

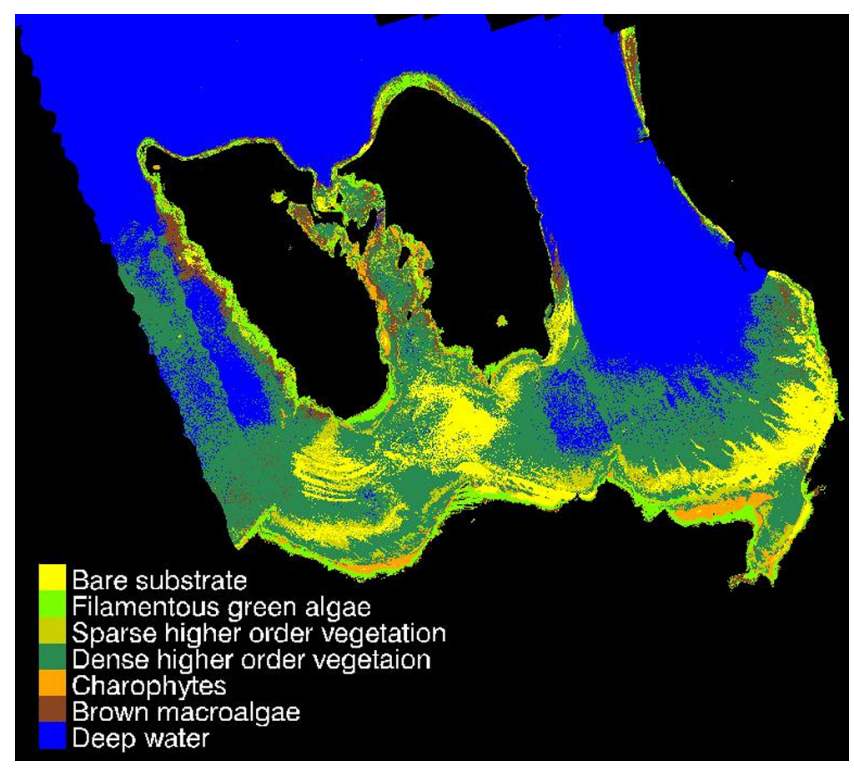

Fig. 9 Benthic habitat map of the Pakri marine area obtained from the CASI airborne imagery using supervised classification and seven benthic classes described in Table 1 and Fig. 2. 
Table 3 Classification accuracy of the hyperspectral CASI image.

\begin{tabular}{|c|c|c|c|c|c|c|c|c|c|}
\hline & & \multicolumn{8}{|c|}{ Ground reference } \\
\hline & & $\begin{array}{c}\text { Bare } \\
\text { substrate }\end{array}$ & $\begin{array}{l}\text { Filam. } \\
\text { green } \\
\text { algae }\end{array}$ & $\begin{array}{l}\text { Dense } \\
\text { higher } \\
\text { veget. }\end{array}$ & Charophytes & $\begin{array}{c}\text { Brown } \\
\text { macroalgae }\end{array}$ & $\begin{array}{l}\text { Sparse } \\
\text { higher } \\
\text { veget. }\end{array}$ & Total & $\begin{array}{c}\text { User } \\
\text { accuracy } \\
(\%)\end{array}$ \\
\hline \multirow{8}{*}{$\begin{array}{l}\text { Map } \\
\text { classes }\end{array}$} & Bare substrate & 20 & 0 & 1 & 0 & 0 & 1 & 22 & 91 \\
\hline & Filam. green algae & 0 & 22 & 1 & 2 & 2 & 0 & 27 & 81 \\
\hline & Dense higher veget. & 0 & 2 & 49 & 2 & 7 & 0 & 60 & 82 \\
\hline & Charophytes & 2 & 1 & 2 & 15 & 1 & 0 & 21 & 71 \\
\hline & Brown macroalgae & 0 & 2 & 3 & 0 & 21 & 0 & 26 & 80 \\
\hline & Sparse higher veget. & 1 & 2 & 1 & 0 & 1 & 5 & 10 & 50 \\
\hline & Total & 23 & 29 & 57 & 19 & 32 & 6 & 166 & \\
\hline & Producer accuracy (\%) & 87 & 76 & 86 & 79 & 60 & 83 & & \\
\hline
\end{tabular}

Note: overall accuracy $=80 \%$.

Bold values indicate the number of correctly classified pixels.

$60 \%$ of pixels identified as "brown macroalga" during the field work were classified to the correct habitat class. The lowest producer accuracy indicates that the class "brown macroalgae" was the most underestimated in our study area.

\section{Discussion}

Hyperspectral remote sensing technology has emerged as a promising tool for studying marine as well as fresh water benthic environments, but at the same time it is subject to several limitations. Benthic information can be retrieved only up to some maximum depth limit that depends on both environmental and instrumental factors. ${ }^{62}$ One of the key factors influencing the maximum depth from which the benthic information can be detected is the optical properties of the water column. Optical properties in turn are a function of the concentration of water column constituents.

The results obtained by different researchers in clear oceanic waters have demonstrated that both benthic substrate and water depth can be retrieved with high accuracy from remotely sensed hyperspectral imagery. The extensions of these techniques to complex waters have still had less attention. Moreover, the depth limits to which benthic substrate and bathymetry mapping is practical in such waters is still poorly defined. This study aimed at retrieving information about benthic substrates and bathymetry in the complex Baltic Sea waters and defining limits for potential benthic detection.

Various methods for atmospheric correction have been used by different authors to compensate for the effect of atmosphere on remote sensing images. Atmospheric correction may be applied using a "deep water" subtraction method, by collecting spectral information from the image (scene-based empirical approach) or by modeling radiation transmission through atmosphere. We used the FLAASH atmospheric correction method, which produced reliable water reflectance spectra. Corrected reflectance spectra generally matched the shapes of in situ measured spectra.

Some authors have shown that the implementation of WCC can increase benthic substrate classification accuracy. ${ }^{63,64}$ Moreover, accurate quantification of bottom reflectance is essential for establishing relationships between remote sensing signals and benthic features of interest. For example, the elimination of the overlying water column influence is required to quantitatively determine benthic vegetation absolute density, biomass, LAI, and primary production. However, the success of accurate substrate spectral retrieval in turbid waters is more dependent on the accuracy and precision of the reflectance, attenuation, and depth measurements than it is in clear waters. $^{65}$ 
Validation of the WCC is desirable using in situ bottom reflectance; however, it can be difficult to measure in the field. ${ }^{44}$ Therefore, this kind of comparative information is very limited in the literature. ${ }^{15,23,27,66}$ In this study, the performance of the Maritorena model for WCC was estimated by comparing the corrected bottom spectra with measured substrate spectra from our spectral library. Our results showed that the reflectance magnitude of WCC spectra started to increase with increasing depth. Vegetation spectra were highly overcorrected in green spectral regions at depths over $2.0 \mathrm{~m}$, whereas blue and NIR spectral regions showed negative values at those depths. Nonetheless, it seems that the WCC model succeeded in retrieving the spectral shape for some of the substrates but failed to retrieve their correct magnitudes. The latter was also concluded by Zoffoli et al. ${ }^{44}$

Shallow sea areas, where water depth does not exceed 2 to $3 \mathrm{~m}$, are widespread in Estonian coastal waters. The Maritorena model managed to retrieve spectral shapes of some substrates from water depths down to 2 to $3 \mathrm{~m}$. Retrieving benthic information from such a depth would be a great benefit in coastal sea studies. However, the model failed to retrieve the spectral shapes of brown macroalgae and higher order vegetation even in very shallow water. Therefore, it was concluded that the currently applied WCC method was not very useful in optically complex waters.

The depth limit for benthic substrate detection varies depending on the water column optical properties and the magnitude of substrate reflectance. $K_{d}$ is one of the most important optical properties for characterizing the water column. In clear waters, $K_{d}$ shows low attenuation coefficient values in blue and green wavelengths and increases exponentially in red and NIR spectral regions because of the increasing absorption of pure water at these wavelengths ${ }^{67,68}$ Generally, underwater habitats cannot be detected by wavelengths past $680 \mathrm{~nm}$ due to the great attenuation of pure water. ${ }^{39}$ In our turbid coastal waters, the attenuation is high both in NIR and blue spectral regions because of the absorption of water and elevated levels of dissolved and particulate matters in the water column, respectively. The lowest $K_{d}$ values occurred in the green spectral region between 500 and $600 \mathrm{~nm}$, allowing for the greatest detectability limits for retrieving information about benthic habitats.

The magnitude of substrate reflectance greatly influences detectability limits-the brighter the substrates the further the depth threshold. In our case, the depth threshold for sand was $\sim 7.5 \mathrm{~m}$ at the wavelengths of furthest light penetration, whereas for higher plants and brown macroalgae it was $\sim 3.0 \mathrm{~m}$. However, the value of $K_{d}$ changes together with the concentrations of CDOM, suspended sediment, and phytoplankton. If the concentrations of water column constituents differ significantly from the concentrations measured in this study, the detectability depth limits in the same study area may be somewhat different.

Coastal uses around the Baltic Sea have evolved significantly over recent decades. Fisheries, aquaculture, shipping, offshore wind farms, gas pipes, coastal defense systems, extraction of building materials, tourist industry, and marine conservation all compete for the marine space. To enable a sustainable coastal zone management, we need to increase knowledge on the Baltic Sea marine habitats, which demands large-scale habitat classification and mapping. In this study, a benthic habitat distribution map was retrieved from the CASI sea surface reflectance image. Although our initial aim was to first apply WCC to CASI sea surface spectra to retrieve bottom reflectance and then classify CASI bottom reflectance image, it turned out to be impractical due to the unsatisfied WCC results. As such, we did not see the benefits of applying the classification procedure to the CASI bottom reflectance image.

The accuracy assessment showed relatively high classification accuracy $(80 \%)$ when limited to the water depth of $<3 \mathrm{~m}$. However, the map producer's knowledge of the study area helped to decide whether it is necessary to add or remove training ROI's to produce a more accurate benthic habitat map. Therefore, the quality of classification maps is determined by the selection of training regions.

The knowledge we gained from this study assures that our aim in further classification assignments should be: (1) to remain at the depth limit of $3 \mathrm{~m}$ while mapping different submerged vegetation classes in the Baltic Sea and (2) to expand the depth limit to 6 to $7 \mathrm{~m}$ while aiming at differentiating bright unvegetated substrates from deep water.

Blue spectral bands are used for bathymetry mapping in optically clear waters as this spectral region allows for the furthest distance of light penetration. ${ }^{33,65,69}$ The Baltic Sea is an optically 
complex water body with high concentrations of CDOM characterized by strong absorption in the blue spectral region. Therefore, the light penetration is limited in the blue spectral range and optimum wavelengths for bathymetry mapping should be shifted toward longer wavelengths. It has been concluded that a blue-green band ratio gives poor correlations with water depths in the Baltic Sea, moderate correlations have been obtained using green-red spectral regions, and the strongest correlations have been achieved using green-yellow spectral regions. ${ }^{37}$ Therefore, a green-yellow band ratio was also used in this study for bathymetry retrieval.

Bathymetry retrieval from remote sensing images relies on the physical basis that changes in spectral radiance reflected from the water bottom are directly related to the water depth changes. Beyond a certain depth, however, any additional increases in depth lead to changes in benthic reflectance that is too small to be resolved by the imaging system. ${ }^{62}$ Maximum depth for bathymetry detection was not calculated in this study, but it can be calculated using equations provided in Refs. 59 and 62. Instead, the depth limit to which bathymetric mapping is practical in our study site was estimated from validation plots. Validation plots between in situ measured depths and modeled water depths indicated when depth retrieval performance began to deteriorate. This study indicated that the used bathymetry model started to slightly underestimate depths in water deeper than $3.5 \mathrm{~m}$ (Fig. 8). This indication was supported by the earlier results, which showed that the underestimation of water depths is evident in the Baltic Sea near-coastal areas and bays in waters over 3.0 to $3.5 \mathrm{~m} .{ }^{37}$ This depth limit can be extended to depths over $4.0 \mathrm{~m}$ in open sea areas. ${ }^{37}$ This means that, beyond this depth limit, the bathymetry is retrieved with substantially lower accuracy.

\section{Conclusion}

Different preprocessing methods are used in remote sensing image interpretation to allow for the highest level of information extraction. Sea surface reflectance was retrieved from the CASI hyperspectral imagery after completing three image correction steps: atmospheric correction, MNF transform, and glint correction. Retrieved CASI sea surface reflectance spectra generally matched the magnitudes and shapes of in situ measured spectra. At the same time, the applied WCC algorithm did not yield accurate bottom reflectance spectra in our study area.

One of the goals of this study was to assess the benthic substrate detectability limits in the complex Baltic Sea waters. The depth limit for benthic substrate detection depends on the water column optical properties and the magnitude of substrate reflectance. Results of this study showed that the depth threshold for the brightest substrate (sand) was $\sim 7.5 \mathrm{~m}$ at the wavelengths of furthest light penetration, $5.0 \mathrm{~m}$ for brighter vegetation (green macroalgae), and $3.0 \mathrm{~m}$ for darker vegetation (higher plants and brown macroalgae). The depth limit to which bathymetric mapping is practical in the Baltic Sea coastal waters was estimated to be around 3.5 to $4.0 \mathrm{~m}$.

Another goal of this study was to generate benthic habitat and bathymetry maps from hyperspectral CASI image, as both are commonly required by scientists and managers. It has been shown that the implementation of the WCC can increase benthic habitat classification accuracy. However, our results showed that this is not the case in optically complex waters. The overall accuracy of the retrieved benthic habitat map from the Pakri study area was $80 \%$, and this was obtained using atmospherically and glint corrected CASI imagery without the WCC. Validation of retrieved bathymetry map revealed an $R^{2}$ value of 0.88 with an RMSE of $0.32 \mathrm{~m}$.

\section{Acknowledgments}

This research was funded by the Estonian Research Council (Grant Nos. PUT1049 and PUT PRG302) and the Estonian Environmental Investment Centre. We are grateful to Teemar Püss, Kaire Kaljurand, and Tiia Möller for help in field works. We wish to thank the Latvian Institute for Environmental Solutions for acquiring CASI data and Estonian Land Board for aerial photographs. The authors declare no conflicts of interest. 


\section{References}

1. S. Maritorena, A. Morel, and B. Gentili, "Diffuse reflectance of oceanic shallow waters: influence of water depth and bottom albedo," Limnol. Oceanogr. 39, 1689-1703 (1994).

2. P. Nieto, "Classifying benthic habitats and deriving bathymetry at the Caribbean Netherlands using multispectral imagery. Case study of St. Eustatius," Master's Thesis, Wageningen University and Research Centre, The Netherlands (2013).

3. P. C. Valentine, B. J. Todd, and V. E. Kostylev, "Classification of marine sublittoral habitats, with application to the northeastern North America region," Am. Fish. Soc. Symp. Ser. 41, 183-200 (2005).

4. A. Fornes et al., "Mapping Posidonia Oceanica from IKONOS," ISPRS J. Photogramm. Remote Sens. 60, 315-322 (2006).

5. G. Casal et al., "Remote sensing with SPOT-4 for mapping kelp forests in turbid waters on the south European Atlantic shelf," Estuarine Coastal Shelf Sci. 91, 371-378 (2011).

6. S. Andrefouet et al., "Multi-site evaluation of IKONOS data for classification of tropical coral reef environments," Remote Sens. Environ. 88, 128-143 (2003).

7. E. Hochberg, S. Andrefouet, and M. Tyler, "Sea surface correction of high spatial resolution Ikonos images to improve bottom mapping in near-shore environments," IEEE Trans. Geosci. Remote Sens. 41, 1724-1729 (2003).

8. E. Belluco et al., "Mapping salt-marsh vegetation by multispectral and hyperspectral remote sensing," Remote Sens. Environ. 105, 54-67 (2006).

9. T. Kutser, I. Miller, and D. L. B. Jupp, "Mapping coral reef benthic substrates using hyperspectral space-borne images and spectral libraries," Estuarine Coastal Shelf Sci. 70, 449-460 (2006).

10. D. Mishra et al., "Benthic habitat mapping in tropical marine environments using QuickBird multispectral data," Photogramm. Eng. Remote Sens. 72, 1037-1048 (2006).

11. S. L. Benfield et al., "Mapping the distribution of coral reefs and associated sublittoral habitats in Pacific Panama: a comparison of optical satellite sensors and classification methodologies," Int. J. Remote Sens. 28, 5047-5070 (2007).

12. L. Bertels et al., "Mapping of coral reefs using hyperspectral CASI data; a case study: Fordata, Tanimbar, Indonesia," Int. J. Remote Sens. 29, 2359-2391 (2008).

13. S. Bejarano et al., "Combining optical and acoustic data to enhance the detection of Caribbean forereef habitats," Remote Sens. Environ. 114, 2768-2778 (2010).

14. G. Casal et al., "Mapping benthic macroalgal communities in the coastal zone using CHRISPROBA mode 2 images," Estuarine Coastal Shelf Sci. 94, 281-290 (2011).

15. J. D. O'Neill, M. Costa, and T. Sharma, "Remote sensing of shallow coastal benthic substrates: in situ spectra and mapping of eelgrass (Zostera marina) in the Gulf Islands National Park Reserve of Canada," Remote Sens. 3, 975-1005 (2011).

16. E. Vahtmäe and T. Kutser, "Classifying the Baltic Sea shallow water habitats using imagebased and spectral library methods," Remote Sens. 5, 2451-2474 (2013).

17. I. A. Leiper et al., "Mapping coral reef benthos, substrates and bathymetry, using compact airborne spectrographic imager (CASI) data," Remote Sens. 6, 6423-6445 (2014).

18. L. Reshitnyk et al., "Evaluation of WorldView-2 and acoustic remote sensing for mapping benthic habitats in temperate coastal Pacific waters," Remote Sens. Environ. 153, 7-23 (2014).

19. S. Andrefouet et al., "Change detection in shallow coral reef environments using Landsat 7 ETM+ data," Remote Sens. Environ. 78, 150-162 (2001).

20. A. G. Dekker, V. E. Brando, and J. M. Anstee, "Retrospective seagrass change detection in a shallow coastal tidal Australian lake," Remote Sens. Environ. 97, 415-433 (2005).

21. M. Gullström et al., "Assessment of changes in the seagrass-dominated submerged vegetation of tropical Chwaka Bay (Zanzibar) using satellite remote sensing," Estuarine Coastal Shelf Sci. 67, 399-408 (2006).

22. M. Lyons, S. Phinn, and C. Roelfsema, "Integrating QuickBird multi-spectral satellite and field data: mapping bathymetry, seagrass cover, seagrass species and change in Moreton Bay, Australia in 2004 and 2007," Remote Sens. 3, 42-64 (2011). 
23. H. M. Dierssen and R. C. Zimmerman, "Ocean color remote sensing of seagrass and bathymetry in the Bahamas Banks by high-resolution airborne imagery," Limnol. Oceanogr. 48, 444-455 (2003).

24. S. Andrefouet et al., "Use of in situ and airborne reflectance for scaling-up spectral discrimination of coral reef macroalgae from species to communities," Mar. Ecol. Prog. Ser. 283, 161-177 (2004).

25. S. Phinn et al., "Mapping seagrass species, cover and biomass in shallow waters: an assessment of satellite multi-spectral and airborne hyper-spectral imaging systems in Moreton Bay (Australia)," Remote Sens. Environ. 112, 3413-3425 (2008).

26. R. Pu et al., "Mapping and assessing seagrass along the western coast of Florida using Landsat TM and EO-1 ALI/HYPERION imagery," Estuarine Coastal Shelf Sci. 115, 234-245 (2012).

27. V. J. Hill et al., "Evaluating light availability, seagrass biomass and productivity using hyperspectral airborne remote sensing in Saint Joseph's Bay, Florida," Estuaries Coasts 37, 1467-1489 (2014).

28. C. M. Duarte, "Reviews and syntheses: hidden forests, the role of vegetated coastal habitats in the ocean carbon budget," Biogeosciences 14, 301-310 (2017).

29. H. M. Dierssen et al., "Benthic ecology from space: optics and net primary production in seagrass and benthic algae across the Great Bahama Bank," Mar. Ecol. Prog. Ser. 411, 1-15 (2010).

30. K. E. Joyce and S. R. Phinn, "Hyperspectral analysis of chlorophyll content and photosynthetic capacity of coral reef substrates," Limnol. Oceanogr. 48, 489-496 (2003).

31. J. C. Brock et al., "Northern Florida reef tract benthic metabolism scaled by remote sensing," Mar. Ecol. Prog. Ser. 312, 123-139 (2006).

32. D. R. Lyzenga, "Passive remote sensing techniques for mapping water depth and bottom features," Appl. Opt. 17, 379-383 (1978).

33. R. P. Stumpf, K. Holderied, and M. Sinclair, "Determination of water depth with high resolution satellite imagery over variable bottom types," Limnol. Oceanogr. 48, 547-556 (2003).

34. A. G. Dekker et al., "Intercomparison of shallow water bathymetry, hydro-optics, and benthos mapping techniques in Australian and Caribbean coastal environments," Limnol. Oceanogr. Methods 9, 396-425 (2011).

35. J. F. Bramante, D. K. Raju, and T. M. Sin, "Multispectral derivation of bathymetry in Singapore's shallow, turbid waters," Int. J. Remote Sens. 34, 2070-2088 (2013).

36. G. Doxani et al., "Shallow-water bathymetry over variable bottom types using multispectral Worldview-2 image," ISPRS Int. Arch. Photogramm. Remote Sens. Spat. Inf. Sci. XXXIXB8, 159-164 (2012).

37. E. Vahtmäe and T. Kutser, "Airborne mapping of shallow water bathymetry in the optically complex waters of the Baltic Sea," J. Appl. Remote Sens. 10, 025012 (2016).

38. G. Casal et al., "Assessment of empirical algorithms for bathymetry extraction using Sentinel-2 data," Int. J. Remote Sens. 40, 2855-2879 (2019).

39. J. T. O. Kirk, Light and Photosynthesis in Aquatic Ecosystems, 2nd ed., Cambridge University Press, Cambridge (1994).

40. A. G. Dekker et al., "Imaging spectrometry of water," in Imaging Spectrometry, F. D. Van der Meer and S. M. De Jong, Eds., pp. 307-359, Kluwer Academic Publishers, Netherland (2001).

41. J. D. Hedley, A. R. Harborne, and P. J. Mumby, "Simple and robust removal of sun glint for mapping shallow-water benthos," Int. J. Remote Sens. 26, 2107-2112 (2005).

42. E. J. Hochberg and M. J. Atkinson, "Capabilities of remote sensors to classify coral, algae, and sand as pure and mixed spectra," Remote Sens. Environ. 85, 174-189 (2003).

43. S. Kay, J. Hedley, and S. Lavender, "Sun glint correction of high and low spatial resolution images of aquatic scenes: a review of methods for visible and near-infrared wavelengths," Remote Sens. 1, 697-730 (2009).

44. M. L. Zoffoli, R. Frouin, and M. Kampel, "Water column correction for coral reef studies by remote sensing," Sensors 14, 16881-16931 (2014). 
45. T. Kutser et al., "Mapping coloured dissolved organic matter concentration in coastal waters," Int. J. Remote Sens. 30, 5843-5849 (2009).

46. T. Kutser et al., "Field measurements of spectral backscattering coefficient of the Baltic Sea and boreal lakes," Boreal Environ. Res. 14, 305-312 (2009).

47. T. Kutser et al., "Monitoring cyanobacterial blooms by satellite remote sensing," Estuarine Coastal Shelf Sci. 67, 303-312 (2006).

48. T. Möller, J. Kotta, and G. Martin, "Effect of observation method on the perception of community structure and water quality in a brackish water ecosystem," Mar. Ecol. 30, 105-112 (2009).

49. A. Morel and B. Gentili, "Diffuse reflectance of oceanic waters. II Bidirectional aspects," Appl. Opt. 32, 6864-6879 (1993).

50. K. Toming et al., "Mapping water quality parameters with sentinel-3 ocean and land colour instrument imagery in the Baltic Sea," Remote Sens. 9, 1070 (2017).

51. S. M. Adler-Golden et al., "Atmospheric correction for shortwave spectral imagery based on MODTRAN4," Proc. SPIE 3753, 61-69 (1999).

52. W. J. Moses et al., "Impact of signal-to-noise ratio in a hyperspectral sensor on the accuracy of biophysical parameter estimation in case II waters," Opt. Express 20, 4309-4330 (2012).

53. C. Vaiphasa, "Consideration of smoothing techniques for hyperspectral remote sensing," ISPRS J. Photogramm. Remote Sens. 60, 91-99 (2006).

54. D. Schläpfer and R. Richter, "Spectral polishing of high resolution imaging spectroscopy data," in 7th EARSEL SIG-IS Workshop Imaging Spectrosc., Edinburgh, Scotland, pp. 11.04-13.04 (2011).

55. G. Luo et al., "Minimum noise fraction versus principal component analysis as a preprocessing step for hyperspectral imagery denoising," Can. J. Remote Sens. 42, 106-116 (2016).

56. A. A. Green et al., "A transformation for ordering multispectral data in terms of image quality with implications for noise removal," IEEE Trans. Geosci. Remote Sens. 26, 65-74 (1988).

57. C. D. Mobley, "Estimation of the remote-sensing reflectance from above-surface measurements," Appl. Opt. 38, 7442-7455 (1999).

58. J. Kotta et al., "In-air spectral signatures of the Baltic Sea macrophytes and their statistical separability," J. Appl. Remote Sens. 8, 083634 (2014).

59. C. J. Legleiter et al., "Passive optical remote sensing of river channel morphology and instream habitat: physical basis and feasibility," Remote Sens. Environ. 93, 493-510 (2004).

60. T. Kutser, E. Vahtmäe, and J. Praks, "A sun glint correction method for hyperspectral imagery containing areas with non-negligible water leaving NIR signal," Remote Sens. Environ. 113, 2267-2274 (2009).

61. E. Vahtmäe et al., "Detecting patterns and changes in a complex benthic environment of the Baltic Sea," J. Appl. Remote Sens. 5, 053559 (2011).

62. C. J. Legleiter and R. L. Fosness, "Defining the limits of spectrally based bathymetric mapping on a large river," Remote Sens. 11, 665 (2019).

63. P. J. Mumby et al., "Benefits of water column correction and contextual editing for mapping coral reefs," Int. J. Remote Sens. 19, 203-210 (1998).

64. S. J. Purkis and R. Pasterkamp, "Integrating in situ reef-top reflectance spectra with Landsat TM imagery to aid shallow-tropical benthic habitat mapping," Coral Reefs 23, 5-20 (2004).

65. P. J. Werdell and C. S. Roesler, "Remote assessment of benthic substrate composition in shallow waters using multispectral reflectance," Limnol. Ocenaogr. 48, 557-567 (2003).

66. D. R. Mishra et al., "Enhancing the detection and classification of coral reef and associated benthic habitats: a hyperspectral remote sensing approach,” J. Geophysic. Res. 112, C08014 (2007).

67. D. Mishra et al., "Characterizing the vertical diffuse attenuation coefficient for downwelling irradiance in coastal waters: implications for water penetration by high resolution satellite data," ISPRS J. Photogramm. Remote Sens. 60, 48-64 (2005).

68. A. Simon and P. Shanmugam, "Estimation of the spectral diffuse attenuation coefficient of downwelling irradiance in inland and coastal waters from hyperspectral remote sensing data: validation with experimental data," Int. J. Appl. Earth Obs. Geoinf. 49, 117-125 (2016). 
69. W. J. Hernandez and R. A. Armstrong, "Deriving bathymetry from multispectral remote sensing data," J. Mar. Sci. Eng. 4, 8 (2016).

Ele Vahtmäe received her $\mathrm{PhD}$ in hydrobiology from the University of Tartu in 2009. She is a senior research scientist in the Department of Remote Sensing and Marine Optics of Estonian Marine Institute at the University of Tartu. Her research interests include developing methods for mapping benthic habitats in the Baltic Sea coastal waters using remote sensing methods and integrating optical methods with in situ data for the estimation of benthic vegetation stress responses and primary production.

Biographies of the other authors are not available. 